\title{
Letter to the Editor \\ Subcutaneous Terbutaline Pump for Maintenance of Tocolysis following Arrest of Acute Preterm Labor
}

\author{
Kavita Singh, ${ }^{1}$ Mohammed T. Ansari, ${ }^{1}$ and Laura M. Gaudet ${ }^{2}$ \\ ${ }^{1}$ Clinical Epidemiology Program, the Ottawa Hospital Research Institute, P.O. Box 201B, TOH-General Campus, \\ 501 Smyth Rd, Ottawa, ON, Canada K1H 8L6 \\ ${ }^{2}$ Maternal Fetal Medicine, Horizon Health Network, Room 2510, 135 MacBeath Avenue, Moncton, NB, Canada E1C 6Z8 \\ Correspondence should be addressed to Kavita Singh; kasingh@ohri.ca
}

Received 6 August 2013; Accepted 13 August 2013; Published 31 March 2014

Academic Editor: Everett Magann

Copyright (C) 2014 Kavita Singh et al. This is an open access article distributed under the Creative Commons Attribution License, which permits unrestricted use, distribution, and reproduction in any medium, provided the original work is properly cited.

Drs. Elliott and Morrison recently published a narrative review about the effectiveness of oral and subcutaneous maintenance of tocolytic agents following successful arrest of acute preterm labor [1]. The authors conclude that subcutaneous terbutaline pump is beneficial and safe for maintenance of tocolysis based on all the available evidence.

While the authors have provided an exhaustive list of the 46 published studies that have examined the terbutaline pump, we would like to express some concerns about the interpretations of this evidence. The authors have formed conclusions without assessing study quality or synthesizing results. In addition, several of the studies cited are single-arm case series and we would be hesitant to draw any conclusions about the efficacy based on this weak study design.

We were commissioned by the Agency for Healthcare Research and Quality to evaluate the benefits and harms of subcutaneous terbutaline pump for maintenance of tocolysis by conducting a systematic review of the literature $[2,3]$. Using prespecified eligibility criteria, we included 14 unique studies [3-17]. The evidence base that we relied on to form our conclusions included all randomized and comparative observational studies. These studies have been cited by Drs. Elliott and Morrison. Of the remaining 33 studies cited by the authors, we had identified and excluded 29; primarily because these studies did not include a comparator group (i.e., they were single-arm studies). The 4 studies that were not identified by our search [18-21] would also have been excluded because there were no nonpump controls.
These 14 studies were of lower quality (medium to high risk of bias) and several studies examined data from one proprietary database. Although we found that the pump was beneficial for some outcomes (i.e., neonatal death, incidence of delivery $<32$ weeks and $<37$ weeks, and prolonging pregnancy), importantly, these benefits were rated as having low strength of evidence, which means that we have low confidence that the evidence reflects the true effect [22]. The strength of evidence is a subjective-though systematic and transparent-assessment of the reviewers' confidence in the findings based on the overall risk of bias, inconsistency, indirectness, and imprecision of the body of evidence [22]. In addition, there was insufficient data on other clinically important outcomes, such as bronchopulmonary dysplasia, intraventricular hemorrhage, and neonatal and maternal harms.

Our more cautious interpretation about the efficacy and safety of terbutaline pump is based on a systematic review of the evidence and scientific methods for quantitative and qualitative synthesis (i.e., meta-analysis and grading strength of evidence). While we acknowledge that the harms reported by FDA after marketing surveillance do not establish causality [23], we have shown that the evidence for efficacy has limited validity. As such, we maintain that the safety and efficacy of the pump for maintenance tocolysis are unclear. Its use should be limited to the research setting, such as further investigation in an adequately powered, randomized, controlled trial. 


\section{Conflict of Interests}

The authors declare that there is no conflict of interests regarding the publication of this paper.

\section{References}

[1] J. P. Elliott and J. C. Morrison, "The evidence regarding maintenance tocolysis," Obstetrics and Gynecology International, vol. 2013, Article ID 708023, 11 pages, 2013.

[2] L. M. Gaudet, K. Singh, L. Weeks et al., "Terbutaline pump for the prevention of preterm birth. Executive summary," http://www.effectivehealthcare.ahrq.gov/ehc/products/157/782/ Terbutaline-Pump_Execsumm.pdf.

[3] L. M. Gaudet, K. Singh, L. Weeks, B. Skidmore, A. Tsertsvadze, and M. T. Ansari, "Effectiveness of terbutaline pump for the prevention of preterm birth. A systematic review and metaanalysis," PLoS ONE, vol. 7, no. 2, Article ID e31679, 2012.

[4] D. A. Guinn, A. R. Goepfert, J. Owen, K. D. Wenstrom, and J. C. Hauth, "Terbutaline pump maintenance therapy for prevention of preterm delivery: a double-blind trial," American Journal of Obstetrics and Gynecology, vol. 179, no. 4, pp. 874-878, 1998.

[5] K. D. Wenstrom, C. P. Weiner, D. Merrill, and J. Niebyl, "A placebo-controlled randomized trial of the terbutaline pump for prevention of preterm delivery," American Journal of Perinatology, vol. 14, no. 2, pp. 87-91, 1997.

[6] C. Lindenbaum, J. Ludmir, F. B. Teplick, A. W. Cohen, and P. Samuels, "Maternal glucose intolerance and the subcutaneous terbutaline pump," American Journal of Obstetrics and Gynecology, vol. 166, no. 3, pp. 925-928, 1992.

[7] J. C. Morrison, S. P. Chauhan, C. S. Carroll Sr. et al., "Continuous subcutaneous terbutaline administration prolongs pregnancy after recurrent preterm labor," American Journal of Obstetrics and Gynecology, vol. 188, no. 6, pp. 1460-1467, 2003.

[8] A. A. Flick, L. de La Torre, L. E. Roca et al., "An examination of the clinical benefits and cost-effectiveness of tocolytic replacement following recurrent preterm labor," American Journal of Perinatology, vol. 27, no. 1, pp. 53-59, 2010.

[9] L. de La Torre, N. B. Istwan, C. Desch et al., "Management of recurrent preterm labor in twin gestations with nifedipine tocolysis," American Journal of Perinatology, vol. 25, no. 9, pp. 555-560, 2008.

[10] A. Fleming, R. Bonebrake, N. Istwan, D. Rhea, S. Coleman, and G. Stanziano, "Pregnancy and economic outcomes in patients treated for recurrent preterm labor," Journal of Perinatology, vol. 24, no. 4, pp. 223-227, 2004.

[11] F. Lam, N. B. Istwan, D. Jacques, S. K. Coleman, and G. J. Stanziano, "Managing perinatal outcomes: the clinical benefit and cost-effectiveness of pharmacologic treatment of recurrent preterm labor," Managed Care, vol. 12, no. 7, pp. 39-46, 2003.

[12] F. Lam, N. K. Bergauer, D. Jacques, S. K. Coleman, and G. J. Stanziano, "Clinical and cost-effectiveness of continuous subcutaneous terbutaline versus oral tocolytics for treatment of recurrent preterm labor in twin gestations," Journal of Perinatology, vol. 21, no. 7, pp. 444-450, 2001.

[13] J. R. Allbert, C. Johnson, W. E. Roberts, R. W. Martin, K. S. Gookin, and J. C. Morrison, "Tocolysis for recurrent preterm labor using a continuous subcutaneous infusion pump," Journal of Reproductive Medicine for the Obstetrician and Gynecologist, vol. 39, no. 8, pp. 614-618, 1994.
[14] A. C. Regenstein, J. Belluomini, and M. Katz, "Terbutaline tocolysis and glucose intolerance," Obstetrics \& Gynecology, vol. 81, no. 5, part 1, pp. 739-741, 1993.

[15] R. T. Adkins, J. E. van Hooydonk, P. L. Bressman et al., "Prevention of preterm birth: early detection and aggressive treatment with terbutaline," Southern Medical Journal, vol. 86, no. 2, pp. 157-164, 1993.

[16] F. Lam, P. Gill, M. Smith, J. L. Kitzmiller, and M. Katz, "Use of the subcutaneous terbutaline pump for long-term tocolysis," Obstetrics \& Gynecology, vol. 72, no. 5, pp. 810-813, 1988.

[17] J. C. Morrison, J. R. Allbert, R. C. Floyd, C. S. Bale, C. H. Lou, and K. S. Gookin, "Interval to delivery in high-risk patients: do tocolytic agents really work?" International Journal of Gynecology and Obstetrics, vol. 38, no. 3, pp. 189-193, 1992.

[18] E. Gaziano, W. Wagner, D. Rhea et al., "Extended hospitalization versus outpatient surveillance in twin gestations following inpatient treatment with magnesium sulfate," Obstetrics \& Gynecology, vol. 103, article 34S, 2004.

[19] H. Brown and G. Stanziano, "Differences in pregnancy outcome in medicaid compared with commercially insured patients with preterm labor," Obstetrics \& Gynecology, vol. 105, no. 4, pp. 74S75S, 2005.

[20] C. Rittenberg, R. B. Newman, N. B. Istwan et al., "Medicaid compared with commercially insured twin pregnancies: equivalent outcomes after preterm labor treatment," Obstetrics \& Gynecology, vol. 107, no. 4, article 34S, 2006.

[21] D. McWeeney, R. Miller, D. Rhea et al., "Probability of prematurity by cervical dilatation and gestational age at preterm labor," Obstetrics \& Gynecology, vol. 107, no. 4, article 31S, 2006.

[22] D. K. Owens, K. N. Lohr, D. Atkins et al., "AHRQ series paper 5: grading the strength of a body of evidence when comparing medical interventions-agency for healthcare research and quality and the effective health-care program," Journal of Clinical Epidemiology, vol. 63, no. 5, pp. 513-523, 2010.

[23] US Food and Drug Administration, "FDA Drug Safety Communication: new warnings against use of terbutaline to treat preterm labor," http://www.fda.gov/Drugs/DrugSafety/ ucm 243539.htm. 


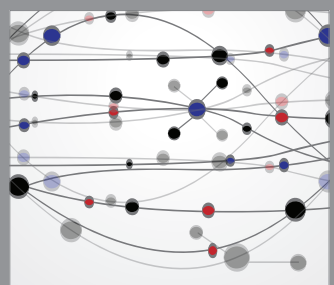

The Scientific World Journal
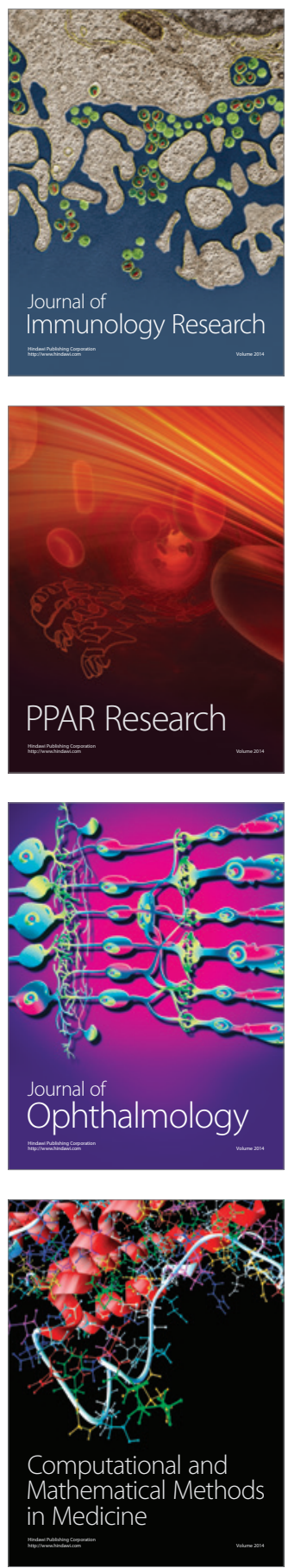

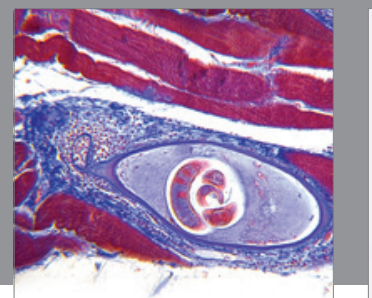

Gastroenterology

Research and Practice
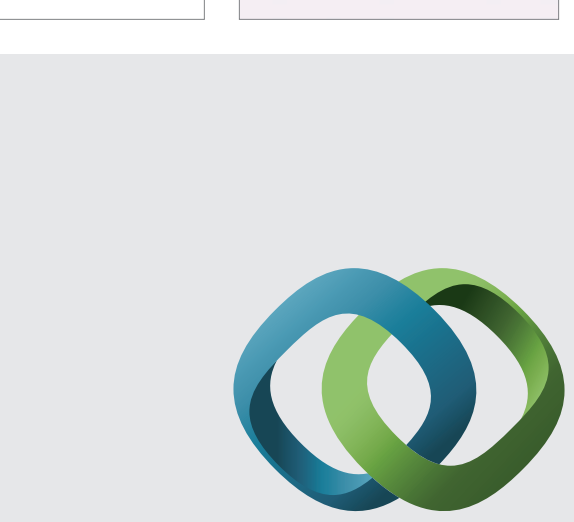

\section{Hindawi}

Submit your manuscripts at

http://www.hindawi.com
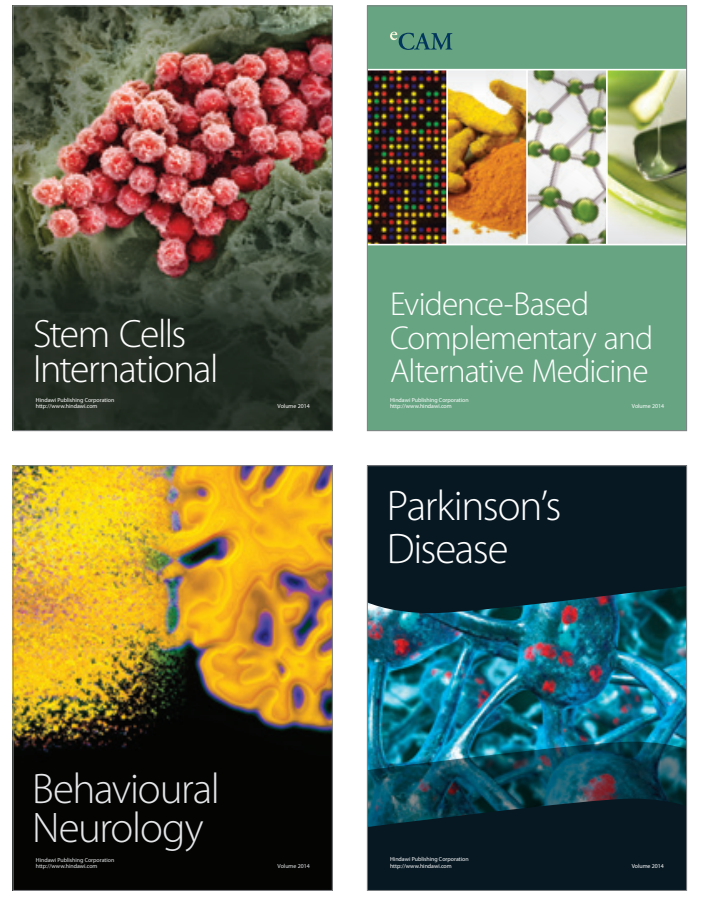
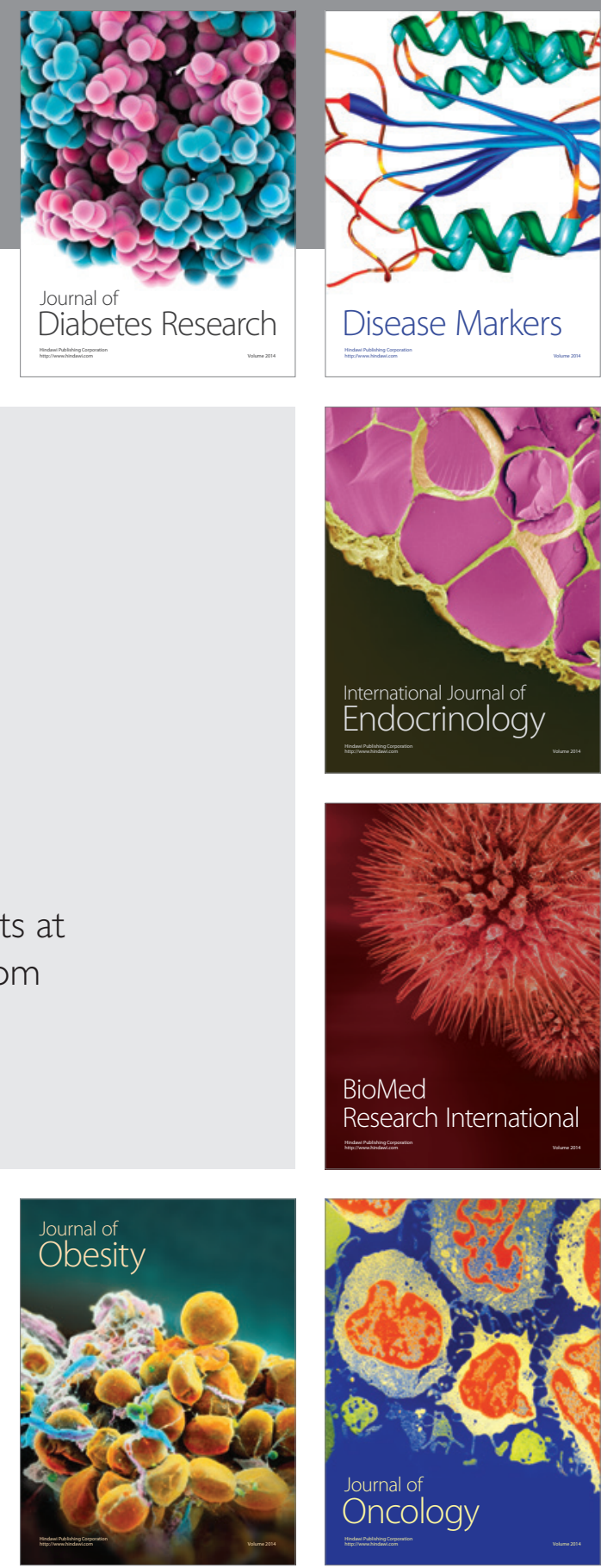

Disease Markers
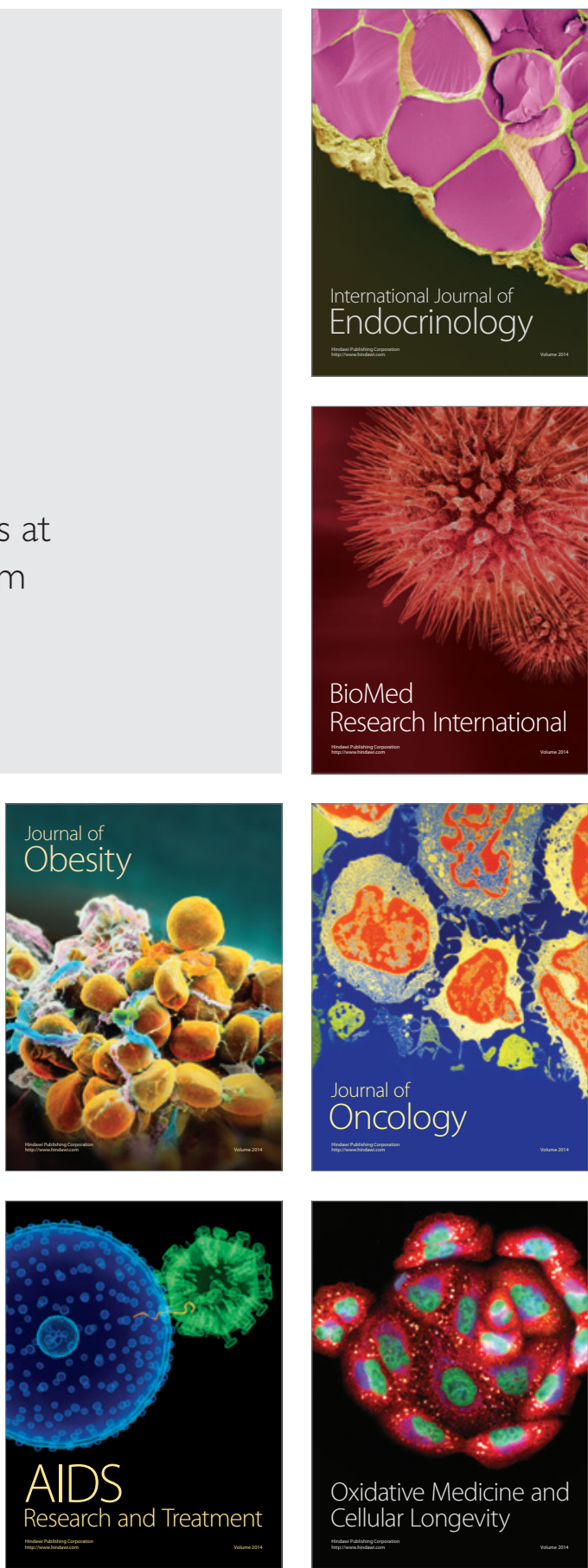